\title{
Users' Perception of their Satisfaction and Experience on a Mobile Cinema Application
}

\author{
Azham Hussain, Emmanuel O.C. Mkpojiogu, Shahida Jamaludin, Kholilah Hilaluddin, \\ Shelena Nathan
}

\begin{abstract}
A subjective usability evaluation was carried out on a mobile cinema application (GSC mobile cinema application) to evaluate the satisfaction and experience of its users. The evaluation was done in two areas: Politeknik Balik Pulau, Pulau Pinang and Kolej Poly-Tech Mara (KPTM) Alor Setar, Kedah. The rationale for the assessment was to evaluate the satisfaction and experience of users in terms of their reactions to the mobile application's interface, terminology and information, application capability and general impression. Twenty volunteers participated in the study. Ten of these participants were at Politeknik Balik Pulau, Pulau Pinang and the other ten were at Kolej Polytech Technology Mara, Alor Setar. The findings indicate that the application's interface was easy to use, simple, consistent, clear, operable, understandable, fast, error recoverable, learnable and enjoyable.
\end{abstract}

Keywords: Mobile application; mobile experience; satisfaction.

\section{INTRODUCTION}

Golden Screen Cinema (GSC) is a mobile cinema application that provides users with a listing of GSC movies with real-time show times and the option to select seats and buy movie tickets using smart mobile devices. GSC mobile app is accessible on all major mobile platforms like the iOS, Android and Windows. The mobile app presents a feature for the e-purchase of movie tickets and popcorn combos. EPurchases can be made at anytime and anywhere via the following channels: Hong Leong Connect, Maybank2u, CIMB Clicks, PayPal, Visa Checkout, AMEX or credit cards. This ticketless option features a QR code on mobile phones and eliminates queue and waiting time at the Cinema gates. Movie admittance is only a scan away for users.

To carry out the usability evaluation, five services offered by the mobile app were selected. These include: download and install the GSC application, login - register account on the GSC app, check on the GSC movie listing, purchase ticket(s), and FastTicket. These services are provided in a 24 hours service to users. The evaluation was conducted in a very conducive environment to enable participants carry out the five tasks. The mobile app's usability evaluation was done using a live version of the app on android smartphones [1-10].

Revised Manuscript Received on June 22, 2019.

Azham Hussain, School of Computing, Universiti Utara Malaysia, 06010 Sintok, Kedah, Malaysia

Emmanuel O.C. Mkpojiogu, School of Computing, Universiti Utara Malaysia, 06010 Sintok, Kedah, Malaysia

Shahida Jamaludin, School of Computing, Universiti Utara Malaysia, 06010 Sintok, Kedah, Malaysia

Kholilah Hilaluddin, School of Computing, Universiti Utara Malaysia, 06010 Sintok, Kedah, Malaysia

Shelena Nathan, Center for Diploma Studies, Universiti Tun Hussein Onn Malaysia, Pagoh Campus, Johor, Malaysia.

\section{METHODOLOGY}

\section{Roles of participants}

Two facilitators were involved in the study. Each of them supervised the evaluation in the study sites. The roles of the facilitators include: i) briefing participants at evaluation sites, ii) observing participants as they carry out tasks, iii) recording the participants as they carry out tasks, iv) interviewing participants after their task activities. In addition, twenty study participants were conscripted to assess the mobile cinema application. There were 10 participants in each evaluation sites. After carrying out the five tasks, each participant completed a subjective questionnaire [11-19].

\section{Participant's Profile}

Out of the 20 participants, 14 were aged 20-25. The gender of the 14 is as follows: female (9), male (5). Of these 14, only 2 had prior experience in the use of the application. Furthermore, out of the 20 study participants, 3 were aged 26-30 and 31-35 respectively. Those in these age categories were only females, 3 each per age group. Also, only 1 in the 26-30 age category had prior experience. No participants in the 31-35 age category had prior usage experience of the mobile app [20-26].

\section{Evaluation Metrics}

The usability evaluation was done to measure the following metrics:

i. Enjoyment

ii. Satisfaction with the interface

iii. Satisfaction with menu button

iv. Satisfaction with text

v. Easy of finding help

These metrics measures users' satisfaction and experience with the user interface. Five task scenarios and questionnaire were given to participant. The task scenarios were based on services offered in the GSC mobile application. In addition, a post-test subjective questionnaire was administered to the participants after they carried out the tasks. The questionnaire had 20 items enclosed in 7 sections, namely: participants' details, interface, terminology \& application information, learning, application capabilities, general impression and overall reaction. The questionnaire was designed with a 10-point Likert scale [27-38].

After the series of tasks, the facilitator asked the participants to rate the subjective measures listed below:

i. How easy is it to find the menu list and interface?

ii. How easy are the instructions and terms in GSC mobile application? 
iii. Are you able to keep track of GSC services in the mobile application?

iv. How accurate is it to predict the capabilities of the services of the mobile application?

v. Other metrics employed in the assessment are shown in Table 1. After the administration of the subjective questionnaire, the data generated were analyzed (see Table 1). Generally speaking, all participants observed that the GSC cinema mobile application was clear, easy to use, satisfying and enjoyable [39-45].

\section{RESULTS AND DISCUSSION}

Table 1 displays metrics, dimensions, percentages and means of the summarized results from the analysis of the subjective questionnaire administered to participants. Participants indicated that highlighting on the screen makes task easier $(86 \%)$. Also, $88 \%$ of participants were of the opinion that interface layouts make tasks easier. Furthermore, 92\% of participants revealed that menu items were easy to select. Thus, on average, $87 \%$ of study participants felt that the apps interface was easy to use. Eighty-three percent $(83 \%)$ of study participants believed that the sequence of the menu of the GSC mobile apps interface was clear. Seven-nine percent $(79 \%)$ believed that the instructions to users were also clear. In addition, $88 \%$ of participants felt that tasks can be performed in a straight-forward manner on the interface. Hence, the perceived simplicity of the GSC mobile app is $83 \%$ on the average. While $89 \%$ of users posit that the use of terms throughout the application was consistent (i.e., consistency), 94\% perceived that the messages (feedbacks) which appear on the screen were clear (i.e., clarity). With regard to content, $81 \%$ of participants felt that the application keeps them informed about what it is doing and another $89 \%$ believe that error messages were helpful [46-50].

Table. 1 Metrics, Dimensions, Percentages and Means

\begin{tabular}{|c|c|c|c|c|}
\hline Metrics & 5-Point Scale & Dimensions & $\%$ & $\begin{array}{c}\text { Mea } \\
\mathrm{n}\end{array}$ \\
\hline Highlighting on the screen makes task easier & Not at all - Very much & Ease-of-Use & 86 & \multirow[t]{3}{*}{$87 \%$} \\
\hline Interface layouts make tasks easier & Never - Always & Ease-of-Use & 88 & \\
\hline Menu items are easy to select & Never - Always & Ease-of-Use & 92 & \\
\hline Sequence of menu & Confusing - Clear & Simplicity & 83 & \multirow[t]{3}{*}{$83 \%$} \\
\hline Instructions to the user. & Confusing - Clear & Simplicity & 79 & \\
\hline Tasks can be performed in a straight-forward manner. & Never - Always & Simplicity & 88 & \\
\hline Use of terms throughout application & $\begin{array}{l}\text { Inconsistent - Consis- } \\
\text { tent }\end{array}$ & Consistency & 89 & $89 \%$ \\
\hline Messages (feedback) which appear on screen. & $\begin{array}{c}\text { Inconsistent - Consis- } \\
\text { tent }\end{array}$ & Clarity & 94 & $94 \%$ \\
\hline Application keeps you informed about what it is doing. & Never - Always & Content & 81 & \multirow[t]{2}{*}{$85 \%$} \\
\hline Error messages. & Unhelpful - Helpful & Content & 89 & \\
\hline Learning to operate the application. & Difficult - Easy & Operability & 80 & $80 \%$ \\
\hline Helps messages on the interface. & Confusing - Clear & Understandability & 81 & $81 \%$ \\
\hline Application speed. & $\begin{array}{l}\text { Too slow - Fast } \\
\text { enough }\end{array}$ & Speed & 93 & $93 \%$ \\
\hline Correcting your mistakes. & Difficult - Easy & Recoverability & 85 & $85 \%$ \\
\hline $\begin{array}{l}\text { The needs of both experienced and inexperienced users are } \\
\text { taken into consideration. }\end{array}$ & Never - Always & Learnability & 87 & \multirow[t]{2}{*}{$88 \%$} \\
\hline Exploration of features by trial and error. & $\begin{array}{l}\text { Discouraged - Encour- } \\
\text { aged } \\
\end{array}$ & Learnability & 89 & \\
\hline Interface is aesthetically pleasing. & Not at all - Very much & Enjoyability & 93 & \multirow[t]{4}{*}{$93 \%$} \\
\hline Application is impressive. & Not at all - Very much & Enjoyability & 86 & \\
\hline Application is fun to use. & Not at all - Very much & Enjoyability & 95 & \\
\hline Overall reactions to the application. & $\begin{array}{l}\text { Unimpressive }- \text { Im- } \\
\text { pressive }\end{array}$ & Enjoyability & 96 & \\
\hline
\end{tabular}

Furthermore, $80 \%$ of participants believe that learning to operate the application is easy (i.e., operability). Also, $81 \%$ believe that helps messages on the interface are clear (i.e., understandability). Concerning speed, 93\% posits that the application speed is fast enough. Furthermore, $85 \%$ of participants concur that correcting mistakes of the interface is easy (i.e., recoverability). In addition, while $87 \%$ of participants believed that the needs of both experienced and inexperienced users were taken into consideration in the application, $87 \%$ felt that exploration of features by trial and error was encouraged by the application. Therefore, on average, the perceived learnability for the app is $88 \%$. Ninety-three percent $(93 \%)$ of participants believed that the interface is aesthetically pleasing. Another $86 \%$ felt that the application is very much impressive. Also, $95 \%$ of users believe that the application is very much fun to use. Finally, the overall reaction to the application by $96 \%$ of participants was that it is impressive. On the average, the perceived enjoyability of the application is $93 \%$. In sum, the GSC 
mobile cinema application is perceived by majority of the study participants as usable, satisfying and enjoyable (that is the application supports their having an enriching experience).

\section{CONCLUSION}

In this study, a subjective usability evaluation was done to assess the level of satisfaction and experience (enjoyment) of users of the GSC mobile cinema application. The results showed overwhelmingly that subjectively the application is easy to use, simple, consistent, clear, operable, understandable, fast, error recoverable, learnable and enjoyable etc.

However, in spite of these laudable observations and impressions, the study has some limitations. The number of participants was 20. This number is small for a subjective study of this nature since plenty of opinions are required in such studies. Also, the sampling method was purposive which do not allow for the randomization of subjects. These limitations no doubt limit the external validity of the study. Nonetheless, as this study required that participants first use the application with some prescribed tasks before filling the subjective questionnaire, the results obtained from the study can be reliable as it expresses the deep sentiment of the study participants that provides insight into their satisfaction and experience regarding the application [47-53].

\section{REFERENCES}

1. Hussain, A, Mkpojiogu, EOC, Yahaya, NB \& Bakar, NZBA (2018), A mobile usability assessment of an m-shopping app. Journal of Advanced Research in Dynamical and Control Systems (JARDCS) 10 (SI), 1212-1217.

2. Gündüz, F \& Pathan, ASK (2013), On the key factors of usability in small-sized mobile touch-screen application. Int. J. Multimed. Ubiquitous Eng, 8(3), 115-138.

3. Kaikkonen, A, Kekäläinen, A., Cankar, M, Kallio, T \& Kankainen, A (2005), Usability testing of mobile applications: A comparison between laboratory and field testing. Journal of Usability Studies, 1(1), 4-16.

4. Hussain, A, Mkpojiogu, EOC, Jamalsse, A \& Mohammed, RA (2018), Grab mobile app: a UX assessment on mobile devices. Journal of Advanced Research in Dynamical and Control Systems (JARDCS) 10 (SI) 1233-1238.

5. Liu, F (2008), Usability Evaluations on Websites. School of Art \&Design, Wuhan University of Technology, Wuhan, Hubei Province, p: 141 .

6. Dumas, JS \& Redish, J (1999), A practical Guide to Usability Testing. Intellect Ltd, UK, US.

7. Srivasta, J, Cooley, R, Deshpande, M \& Tan, PN (2000), Web Usage Mining: Discovery and Application of Web Usage Pattern from Web Data. Department of Computer Science and Engineering, University of Minnesota.

8. Mkpojiogu, EOC, Hussain, A \& Hassan, F (2018), A systematic review of usability quality attributes for the evaluation of mobile learning applications for children. ICAST 2018, AIP Conf. Proc. 2016, https://doi.org/10.1063/1.5055494

9. Icela, L (2017), Usability evaluation focused on user experience of repositories related to energy sustainability: A Literature Mapping.

10. Nayebi, F, Desharnais, JM \& Abran, A (2012), The state of the art of mobile application usability evaluation, 2012 25th IEEE Can. Conf. Electr. Comput. Eng., 1-4.

11. Paz, F \& Pow-Sang, JA (2014), Current Trends in Usability Evaluation Methods: A Systematic Review, 2014 7th Int. Conf. Adv. Softw. Eng. Its Appl., pp: 11-15.

12. Hussain, A, Mkpojiogu, EOC \& Suleiman, K (2018), A usability testing of a mobile print shop booking and design application. Journal of Advanced Research in Dynamical and Control Systems (JARDCS) 10 (SI), 1359-1365.

13. Holzinger, A (2005), Usability engineering methods for software developers. Communications of the ACM, 48(1), 71-74.
14. Molich, R, \& Wilson, C (2008), Tips and tricks for avoiding common problems in usability test facilitation. $\mathrm{CHI} 08$ extended abstracts on Human factors in computing systems. ACM, pp: 2379-2382.

15. Hussain, A, Mkpojiogu, EOC, Suleiman, K \& Alhussian, H (2018), A heuristic evaluation of a mobile print and design shopping application. Journal of Advanced Research in Dynamical and Control Systems (JARDCS) 10 (SI), 1457-1462. Buchanan, S, \& Salako, A (2009), Evaluating the usability and usefulness of a digital library. Library Review, 58(9), 638-651.

16. Rubin, J \& Chisnell, D (2008), Handbook of Usability Testing: How to Plan, Design, and Conduct Effective Tests. Canada: John Wiley \& Sons, Inc.

17. Hussain, A, Mkpojiogu, EOC, Abduljabbar, AM \& Almadhagi, AHG (2018). UUM mobile for students: a usability evaluation on two mobile OS platforms. Journal of Advanced Research in Dynamical and Control Systems (JARDCS) 10 (SI), 1514-1519.

18. Gündüz, F \& Pathan, ASK (2012), Usability improvements for touchscreen mobile flight booking application: A case study. 2012 International Conference on Advanced Computer Science Applications and Technologies (ACSAT), IEEE, pp: 49-54.

19. Dillon, A (2002), Beyond usability: process, outcome and affect in human-computer interactions. Canadian Journal of Library and Information Science.

20. Mkpojiogu, EOC \& Hussain, A (2018), Assessing the influence of selfreported requirements importance on the perceived quality of proposed software products. ICAST 2018, AIP Conf. Proc. 2016, 020091, https://doi.org/10.1063/1.5055493

21. Ahmad, N, Boota, MW \& Masoom, AH (2014), Smart Phone Application Evaluation with Usability Testing Approach, J. Softw. Eng. Appl., 7(12), 1045.

22. Brown, ME \& Hocutt, DL (2015), Learning to Use, Useful for Learning: A Usability Study of Google Apps for Education, J. Usability Stud., 10 (4), 160-181.

23. Hussain, A, Mkpojiogu, EOC, Isse, AJ \& Mohammed, RA (2018), Grab mobile application: a usability evaluation. ICAST 2018, AIP Conf. Proc. 2016, 020054, https://doi.org/10.1063/1.5055456

24. ISO 9241-11 (1998), Ergonomic requirements for office work with visual display terminals (vdts)-part 11: Guidance on usability. ISO Standard 9241-11: 1998. International Organization for Standardization.

25. Hussain, A, Mkpojiogu, EOC, Yahaya, NB \& Bakar, NZBA (2018), A mobile usability assessment of carousell mobile app. ICAST 2018, AIP Conf. Proc. 2016. 020053, https://doi.org/10.1063/1.5055455

26. Bartek, V \& Cheatha, MD (2003), Experience Remote Usability Testing, Part 2: Examine the Benefits and downside of Remote Usability Testing. http://www.mendeley.com/research/experience-remoteusability-testing-part-2-examine-benefits-downside-remote-usabilitytesting/.

27. Hussain, A, Mkpojiogu, EOC, Abduljabbar, AM \& Almadhagi, AHG (2018), A usability evaluation of UUM mobile for students app on IOS and android platforms. ICAST 2018, AIP Conf. Proc. 2016, 020052, https://doi.org/10.1063/1.5055454

28. Chau, P. Cole, M, Massey, AP, Montoya-Weiss, M \& O'Keefe, RM (2002), Cultural differences in consumer's online behaviors. Commun. ACM, 45(10), 45-50.

29. Hussain, A, Mkpojiogu, EOC \& Hassan, F (2018), Usability dimensions and sub-dimensions for the evaluation of m-learning apps for children: A review. International Journal of Engineering \& Technology (IJET) 7 (3.20), 291-295.

30. Forsell, C \& Johansson, J (2010), An heuristic set for evaluation in information visualization. Proceedings of the International Conference on Advanced Visual Interfaces, ACM, pp: 199-206.

31. Krippendorff, K (2004), Content Analysis: An introduction to its methodology, (Sage Publications Inc., United States, 2004).

32. Gehrke, D \& Turban, E (1999), Determinants of successful website design: Relative importance and recommendations for effectiveness, Proc. 32nd Hawaii Int. Conf. System Sciences.

33. Harrison, R, Flood, D \& Duce, D (2013), Usability of mobile applications: Literature Review and Rationale for A New Usability Model, 1-16.

34. Hussain, A \& Mkpojiogu, EOC (2015), An application of the ISO/IEC 25010 standard in the quality-in-use assessment of an online health awareness system, J. Teknol., 77(5) 9-13. 
35. El-Gayar, O, Timsina, P, Nawar, N, \& Eid, W (2013), Mobile applications for diabetes self-management: Status and potential, J. Diabetes Sci. Technol., 7(1), 247-262.

36. Naismith, L (2004), Literature review in mobile technologies and learning, NESTA Futur. Ser. ; Rep. 11, p: 44.

37. Hussain, A, Abd Razak, MNF, Mkpojiogu, EOC \& Hamdi, MMF (2017), UX evaluation of a video streaming application with teenage users. Journal of Telecommunication, Electronic \& Computer Engineering (JTEC), 9 (2-11), 129-131.

38. Naslund, JA, Aschbrenner, KA, Marsch, LA \& Bartels, SJ (2016), The future of mental health care: Peer-To-peer support and social media, Epidemiol. Psychiatr. Sci., 25 (2), 113-122.

39. Hussain, A, Isam, M \& Mkpojiogu, EOC (2017), A UX assessment of a mobile recommender app for household electrical energy savings. Journal of Telecommunication, Electronic \& Computer Engineering (JTEC), 9 (2-11)

40. Joo, S, Lin, S \& Lu, K (2011), A Usability Evaluation Model for Academic Library Websites: Efficiency, Effectiveness and Learnability, J. Libr. Inf. Stud., 9(2), 11-26.

41. Toribio-Guzmán, JM, García-Holgado, A, Pérez, FS, García-Peñalvo, FJ \& Martín, MAF (2016), Study of the Usability of the Private Social Network SocialNet using Heuristic Evaluation, Proc. XVII Int. Conf. Hum. Comput. Interact. - Interacción '16, pp: 1-5.

42. Hussain, A, Mkpojiogu, EOC \& Jasin, NMD (2017), Usability metrics and methods for public transportation applications: a systematic review. Journal of Engineering Science and Technology (JESTEC), Special Issue on ISSC'16, 4, 98-105.

43. Chiang, KP \& Dholakia, RR (2003), Factors Driving Consumer Intention to Shop Online: An Empirical Investigation, Journal of Consumer psychology, 13(1\&2), 177-183.

44. Hussain, A, Isam, M \& Mkpojiogu, EOC (2017), A UX assessment of a mobile recommender app for household electrical energy savings. Journal of Telecommunication, Electronic \& Computer Engineering (JTEC), 9 (2-11)

45. Bangor, A, Kortum, P \& Miller, J (2009), Determining what individual SUS scores mean: Adding an adjective rating scale. Journal of Usability Studies, 4(3), 114-123.

46. Hussain, A, Mkpojiogu, EOC, Musa, J \& Mortada, S (2017), A user experience evaluation of amazon kindle mobile application. Proceedings of the $2^{\text {nd }}$ International Conference on Applied Science and Technology (ICAST'17), Kedah, Malaysia. AIP Conference Proceedings 1891 (1), 020060, http://doi.org/10.1063/1.5005393

47. Nielsen, J (1993), Usability Engineering, Academic Press, United States.

48. Hussain, A, Mkpojiogu, EOC, Fadzil, NM \& Hassan, NM (2017), The UX of amila pregnancy on mobile device. Proceedings of the $2^{\text {nd }}$ International Conference on Applied Science and Technology (ICAST'17), Kedah, Malaysia. IP Conference Proceedings 1891 (1), 020061, http://doi.org/10.1063/1.5005394

49. Kiseol, Y \& Hye-Young, K (2012), Mobile shopping motivation: an application of multiple discriminant analysis, International Journal of Retail \& Distribution Management, 40(10), 778-789.

50. Hussain, A, Mkpojiogu, EOC, Abubakar, H \& Hassan, HM (2017), The usability evaluation of mudah.my on mobile device. Proceedings of the $2^{\text {nd }}$ International Conference on Applied Science and Technology (ICAST'17), Kedah, Malaysia. AIP Conference Proceedings 1891 (1), 020058; http://doi.org/10.1063/1.5005391

51. Ferré, X, Juristo, N, Windl, H \& Constantine, L, Usability engineering Usability Basics, IEEE Softw., 18

52. Hussain, A, Mkpojiogu, EOC, Jamaludin, NH \& Moh, STL (2017), A usability evaluation of Lazada mobile application. Proceedings of the $2^{\text {nd }}$ International Conference on Applied Science and Technology (ICAST'17), Kedah, Malaysia. AIP Conference Proceedings 1891 (1), 020059, http://doi.ord/10.1063/1.5005392

53. Limayem, M, Khalifa, M \& Frini, A (2000), What make consumer buy from internet? A Longitudinal study of online shopping. IEEE Transactions on Systems, Man, and Cybernetics-Part A: Systems and $\mathrm{Hu}-$ mans, 30(4). 